\title{
INTELLIGENT LEARNING ONLINE EDUCATION BERBASIS APLIKASI MOBILE
}

\author{
Randhy Pradana Irsan', Mei Lestari², Ni Wayan Parwati ${ }^{3}$ \\ 1,2,3 Universitas Indraprasta PGRI \\ Jalan Raya Tengah No 80, Kelurahan Gedong, Pasar Rebo, Jakarta Timur \\ 1. randhypradanairsan@gmail.com, ${ }^{2}$ mei.lestari6@gmail.com, ${ }^{3}$ wayan.parwati@gmail.com
}

\begin{abstract}
ABSTRAK
Di era yang semakin modern ini, kecanggihan teknologi terus menerus berkembang pesat.Serta melihat dimana masa pandemic ini menjadi batasan siswa/pelajar dalam berkomunikasi secara langsung dengan guru atau murid lainnya. Melihat hal ini penulis bermaksud menemukan ide yaitu membuat aplikasi Chatbot yang mana aplikasi chatbot ini dapat diajak bertukar pesan khalayak bertukar pesan dengan manusia. Metode penelitian yang digunakan yaitu metode kualitatif mulai dari tahap wawancara sampai observasi langsung ke lapangan. Metode pengembangan yang digunakan yaitu model waterfall karena model ini sangat cocok dan mudah untuk melakukan pengembangan. Hasil dari penelitian ini sangat bermanfaat untuk meningkat kualitas kerja dan tersistematis sehingga mengurangi terjadinya kesalahan dalam pengolahan data, sehingga data yang dihasilkan akan lebih akurat.
\end{abstract}

Kata Kunci: Aplikasi, Intelligent Learning Online Education, Android

\section{ABSTRACT}

In this increasingly modern era, technological sophistication continues to grow rapidly. As well as seeing where this pandemic period is a limitation for students in communicating directly with teachers or other students. Seeing this, the author intends to find an idea, namely to create a Chatbot Application where this chatbot application can be invited to exchange messages, exchange messages with humans. The research method used is a qualitative method starting from the interview stage to direct observation to the field. The development method used is the waterfall model because this model is very suitable and easy to develop. The results of this study are very useful for improving the quality of work and systematically so as to reduce the occurrence of errors in data processing so that the resulting data will be more accurate.

Key Word: Application, Intelligent Learning Online Education, Android

\section{PENDAHULUAN}

Di era yang semakin modern ini, kecanggihan teknologi terus menerus berkembang pesat. Dengan adanya kecanggihan teknologi maka segala kegiatan dan kebutuhan sehari-hari akan terpenuhi dengan mudah. Kecanggihan teknologi dapat membantu segala aspek kehidupan dalam membuat, mengubah, menyimpan, menyampaikan informasi serta menyebarkan informasi.

Perkembangan teknologi tentunya tak luput dari media elektronik salah satunya Smartphone, smartphone adalah ponsel yang di dalamnya berisi inovasi gadget termutakhir (Mabruroh \& Dihan, 2015), android adalah sebuah sistem operasi untuk perangkat mobile berbasis linux yang mencakup sistem operasi, middleware dan aplikasi. (Kuswanto \& Radiansah, 2018). karena smartphone merupakan media yang dapat memberikan kemudahan bagi manusia dalam menyelesaikan pekerjaan.

Dengan adanya smartphone diharapkan mampu menggantikan pekerjaan manusia karena smartphone merupakan sebuah mesin yang tidak mengenal kata "lelah", selain itu smartphone juga dapat mengurangi kesalahan manusia. Dengan demikian masyarakat pada umumnya menggunakan smartphone untuk melakukan kegiatan sehari-hari salah satunya yaitu bertukar pesan elektrik.

Platform Framewok pembangun chatbot AI berbasis cloud, chatbot merupakan salah satu sistem cerdas yang dihasilkan dari pemrosesan Bahasa alami atau Natural Language Processing (NPL) yang merupakan salah satu cabang dari Kecerdasan Buatan atau Artificial Intelligence. Sebuah program komputer yang dapat melakukan percakapan melalui media tulisan. (Ramadhani \& Rusdianto, 2019). Semakin marak pada saat 
ini tanpa kode ataupun digabungkan dengan bahasa pemrograman tertentu. Chatfuel sebagai framework pembangun chatbot atau bot builder telah digunakan oleh beberapa perusahaan tingkat dunia karena hanya memerlukan waktu respon yang singkat dalam menjawab banyak user sekaligus.

\section{METODE PENELITIAN}

Metode penelitian adalah metodologi yang dipilih oleh para ilmuwan untuk menggabungkan dan memimpin percakapan total bagian-bagian eksplorasi dengan cara yang sah dan tepat, seperti membedah substansi yang terkandung dalam komunitas pemeriksaan. Teknik pemeriksaan yang digunakan pencipta untuk mengarahkan penelitian adalah strategi subjektif. Dari hasil penyelidikan ini, para pencipta memimpin pemeriksaan yang pasti atas informasi yang didapat dari lapangan. Data yang sudah dianalisa dan diolah kemudian dibuat sebuah kesimpulan, selanjutnya penulis membuat laporan untuk melampirkan kegiatan yang dilakukan selama proses penelitian di Program Studi Teknik Informatika, Fakultas Teknik dan Ilmu Komputer.

Adapun metode pengumpulan data yang digunakan penulis dalam menyusun penelitian antara lain:

1. Wawancara

Metode wawancara merupakan dialog untuk tujuan tertentu. Wawancara merupakan teknik pengumpulan data yang dilakukan melalui tanya jawab langsung antara peneliti dan narasumber.

2. Metode Observasi

Pengertian metode observasi yang paling sederhana adalah mengamati dan mendengarkan kejadan atau tindakan yang dilakukan oleh pengamat, kemudian menggunakan catatan atau alat bantu lainnya untuk mencatat hasil observasi tersebut.

3. Sumber data melalui website yang ada di internet Penulis mengunjungi beberapa website untuk mengumpulkan artikel dan kutipan yang berkaitan dengan penelitian ini.
Untuk melakukan perincian terhadap masalah yang dihadapi para siswa,maka dilakukannya analisis permasalahan. Analisis permasalahan adalah kegiatan untuk mengidentifikasi elemen-elemen situasi dalam masalah dan memahami elemen mana yang kritis, serta mampu dalam memecahkan permasalahan untuk mendapatkan solusi. Untuk memecahkan permasalahan, maka digunakan diagram fishbone untuk merinci permasalahan. Fungsi utama diagram fishbone adalah untuk identifikasi dan mengelola kemungkinan adanya penyebab dari efek tertentu, dan kemudian membagi akar penyebabnya menjadi beberapa bagian (Rahmah, 2021).

Penulis memilih metode pengembangan Model Waterfall. Model Waterfall merupakan jenis model pengembangan dalam siklus hidup yang klasik berdasarkan pada urutan dan tahap sistem secara terstruktur dan sistematis (Pressman, 2015 : 46) Untuk model pengembangan ini mirip dengan air terjun, dimana setiap tahapan dijalankan secara berurutan dari atas ke bawah. Berikut alur pengembangan sistem dengan model Waterfall:

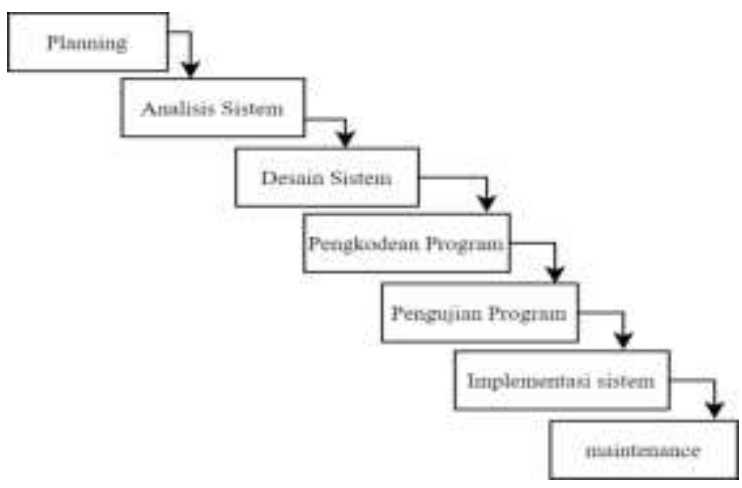

Gambar 1. Model Waterfall

\section{HASIL DAN PEMBAHASAN}

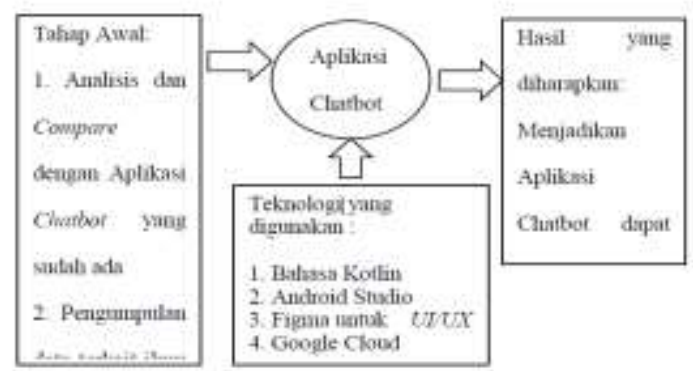

Gambar 2. Kerangka Berpikir 
Berdasarkan analisis masalahan yang sudah dirinci, penulis memberikan solusi untuk alternatif penyelesaian masalah yang ada pada Chatbot yaitu dengan membuat sistem Bertukar pesan dan jalur jalannya program. Alur sistem tersebut dirinci dengan Flowchart. flowchart adalah diagram yang menyatakan aliran proses dengan menggunakan anotasi bidang-bidang geometri, seperti lingkaran, persegi empat, wajik, oval, dan sebagainya untuk merepresentasikan langkah-langkah kegiatan beserta urutannya dengan menghubungkan masing masing langkah tersebut menggunakan tanda panah (Ridlo, 2017).

Degnan dibuatnya kerangka berpikir seperti gambar di atas. Dengan demikian penulis membuat aplikasi chatbot Fisika ini yang mana merupakan aplikasi edukasi yang ditujukan sebagai teman belajar pada masa pandemic, yang mana saat pandemic pelajar diberi batas untuk berinteraksi kepada guru atau temannya.

Aplikasi ini dibuat atau di desain menggunakan Bahasa XML,XML adalah bahasa markup (seperti HTML), XML tidak memiliki label sendiri. Hal in memungkinkan orang menulis XML untuk menciptakan apapun tag yang dibutuhkan. Spesifikasi XML memungkinkan orang untuk mendefinisikan bahasa markup meraka sendiri (Pambudi, 2013).dengan bantuan IDE Android Studio terdapat kemudahankemudahan dalam mendesain Aplikasi ini.

Di era ini sudah banyak Framework yang bisa dipakai untuk membangun aplikasi android ini. Framework adalah sekumpulan fungsi, class, dan aturan-aturan. Berbeda dengan library yang sifatnya untuk tujuan tertentu saja, framework bersifat menyeluruh mengatur bagaimana kita membangun aplikasi (Erinton, 2017).

Adapun untuk aplikasi ini dibuat dengan Bahasa kotlin.Bahasa Kotlin adalah bahasa pemrograman yang dikembangkan oleh JetBrains, perusahaan yang juga mengembangkan IDE Android Studio. Bahasa Kotlin adalah pengembangan dari bahasa Java yang sudah popular sebelumnya. Bahasa Kotlin memiliki fitur-fitur bahasa modern yang lebih dibandingkan bahasa Java (Sibarani, 2018).

Penulis berharap dengan dibuatnya aplikasi chatbot ini dapat menemani pelajar dalam belajar fisika dengan experience seperti sedang bertukar pesan dengan guru tanpa mengganggu gurunya. user experience adalah persepsi seseorang dan responnya dari penggunaan sebuah produk, sistem, atau jasa. User Experiece (UX) menilai seberapa kepuasan dan kenyamanan seseorang terhadap sebuah produk, sistem, dan jasa (Wiryawan, 2011).

Namun yang beda dari bertukar pesan melalui aplikasi ini yaitu pelajar bertukar pesan dengan robot, yang mana robot ini diberi machine learning terkait dengan fisika dan percakapan sehari - hari. ada beberapa masalah yang dihadapi dalam perancangan aplikasi ini yaitu bagaimana mengumpulkan data yang kuantitatif nya sangat banyak sehingga nantinya robot dapat lebih bisa menjawab pesan terkait fisika dan percakapan sehari-hari dengan lebih luas.

Flowchart Halaman Masuk

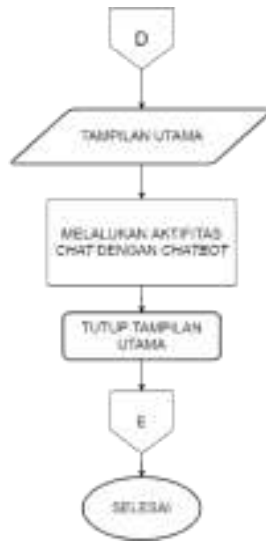

Gambar 3. Flowchart Tampilan Masuk

Algoritma Tampilan Masuk

1) Pada tampilan masuk user mengisikan form email dan password lalu tekan button masuk

2) Jika user belum punya akun, maka user tekan button daftar

3) Maka akan masuk ke Tampilan Daftar

4) Selesai 
Tampilan Masuk

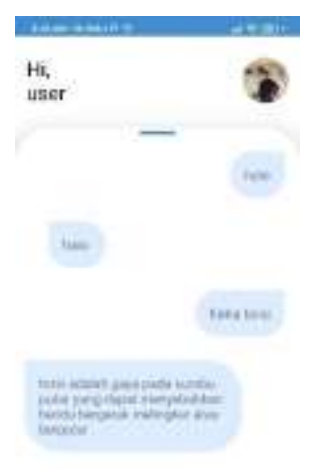

Gambar 4. Tampilan Masuk

Flowchart Halaman Utama

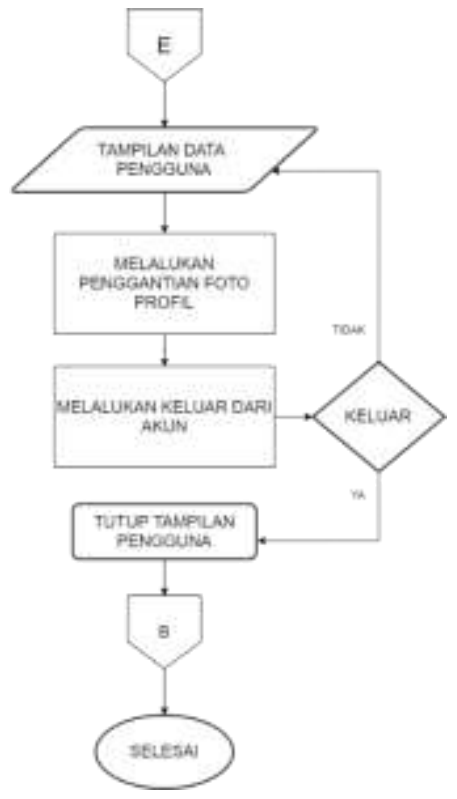

Gambar 5. Flowchart Tampilan Utama sekaligus tampilan chatbot

Algoritma Tampilan Utama

1) Pada Tampilan Utama terdapat proses chatting dengan robot

2) User harus swiped up fragment chat lalu user dapat mengetikan pesan pada textInput lalu tekan button kirim dan user mendapatkan pesan dari robot dalam beberapa detik.

3) Pada Tampilan Utama terdapat juga foto profil. User dapat menekannya dan langsung masuk ke Tampilan Pengguna

4) Selesai
Tampilan Utama

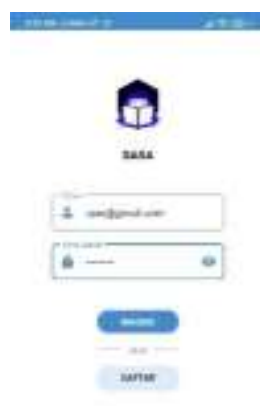

Gambar 5 Tampilan Pembuka

Flowchart Halaman Pengguna

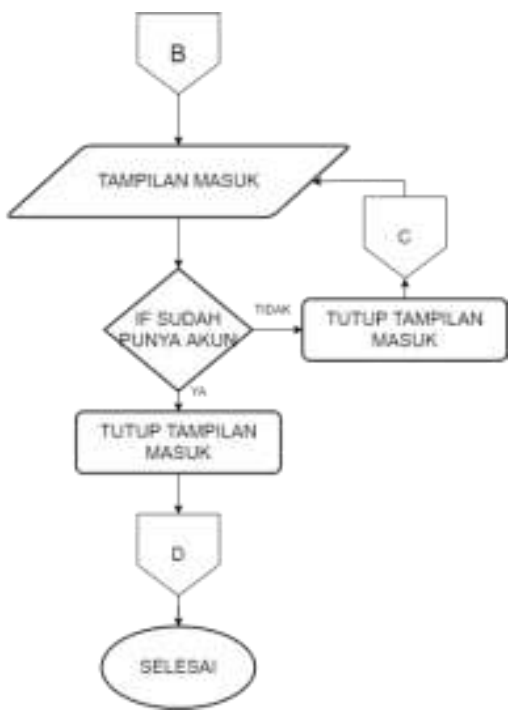

Gambar 6 Flowchart Halaman Pengguna

Algoritma Tampilan Pengguna

1) Pada Tampilan Pengguna terdapat button untuk ganti foto profil

2) Tekan pada button ganti profil, dan user akan di minta untuk memilih foto yang di inginkan, maka foto profil akan terganti sesuai dengan foto pilihannya

3) Pada Tampilan Pengguna terdapat button keluar, jika user menekan button keluar maka user akan keluar dari akun tersebut dan kembali ke Tampilan Masuk

4) Pada Tampilan Pengguna terdapat informasi data pribadi pengguna

5) Selesai 
Tampilan Pengguna

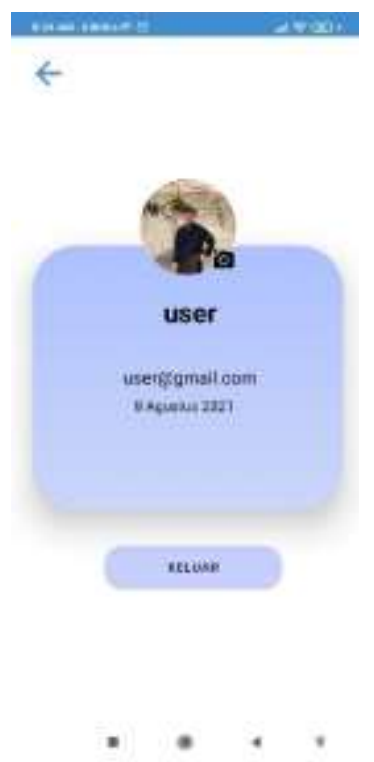

Gambar 7 Tampilan Pembuka

\section{SIMPULAN DAN SARAN}

Dengan terselesaikannya perancangan sistem untuk chatbot, penulis dapat menarik beberapa kesimpulan yaitu, sistem ini dapat dijadikan alat untuk membantu siswa dalam melakukan diskusi terkait dengan teori fisika dan sedikit tambahan diskusi Bahasa seharihari. Selain itu, dapat mengganti profile seperti foto agar dapat memiliki foto terbaru

Adapun saran untuk mengembangkan sistem ini yaitu, sistem yang dibuat masih memiliki kekurangan sehingga perlu pengembangan yang sejalan dengan seiring kemajuan zaman. Selain itu, penambahan fitur diskusi dengan expert yang mana fitur premium yang dapat berdiskusi dengan expertise fisika. Dan untuk kedepannya akan ditambahkannya data-data terbaru dan lebih banyak agar chatbot ini dapat lebih interaktif dalam melakukan tanya jawab denga siswa/user.

\section{UCAPAN TERIMA KASIH}

Dengan pencapaian aplikasi chatbot ini penulis ingin mengucapkan Terima Kasih kepada Orang Tua saya yang selalu mendo'akan saya. Kepada program Bangkit yang telah membuat program yang sangat bermanfaat, serta teman-teman tim Bangkit saya yaitu Bagoes, Rian, Made, Hilmi, Dion yang telah mensupport saya.
DAFTAR PUSTAKA

Erinton, R., Negara, R. M., \& Sanjoyo, D. D. (2017). Analisis Performasi Framework Codeigniter Dan Laravel Menggunakan Web Server Apache. EProceedings of Engineering, 4(3).

Kuswanto, J., \& Radiansah, F. (2018). Media Pembelajaran Berbasis Android Pada Mata Pelajaran Sistem Operasi Jaringan Kelas XI. Jurnal Media Infotama, 14(1).

Mabruroh, C., \& Dihan, F. N. (2015). Smartphone: antara kebutuhan dan elifestyle. Seminar Nasional Informatika (SEMNASIF), 1(5).

Pambudi, A. (2013). Implementasi Model Perangkat Lunak Pelayanan Informasi Kegiatan Belajar Mengajar Tingkat SLTA dengan Berbasis Operating System Android. Jurnal Ilmu Komputer, 9(2), 108-120.

Pressman, R. . (2015). Rekayasa Perangkat Lunak: Pendekatan Praktisi(Buku Dua).

Rahmah, A. (2021). Fishbone Diagram. Rumus.Co.Id.

Ramadhani, R. Z., \& Rusdianto, H. (2019). Rancang Bangun Aplikasi Pusat Informasi Sekolah Dengan Penerapan Chatbot Menggunakan Aiml Berbasis Android Pada Smk Otomotif Al Husna Tangerang. JIKA (Jurnal Informatika), 3(2), 110-116.

Ridlo, I. A. (2017). Panduan pembuatan flowchart. Fakultas Kesehatan Masyarakat, Departemen Administrasi Dan Kebijakan Kesehatan.

Sibarani, N. S., Munawar, G., \& Wisnuadhi, B. (2018). Analisis Performa Aplikasi Android Pada Bahasa Pemrograman Java dan Kotlin. Prosiding Industrial Research Workshop and National Seminar, 9, 319-324.

Wiryawan, M. B. (2011). User Experience (UX) sebagai bagian dari pemikiran desain dalam pendidikan tinggi desain komunikasi visual. Humaniora, 2(2), 1158-1166. 